\title{
Development and Validation of Rapid RP- HPLC Method for Estimation of Ondansetron in the Tablet Dosage Form
}

\author{
R N Varade ${ }^{*}$, P Tak ${ }^{2}$ and H Mishra ${ }^{1}$

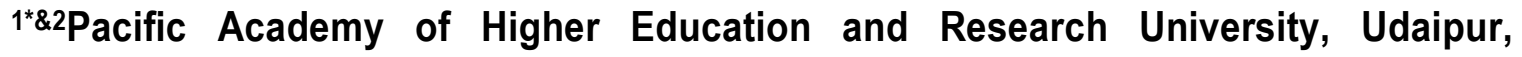 \\ Rajasthan, India-313024. \\ ${ }^{1} \mathrm{~K} . J$. Somaiya Institute of Engineering and Information Technology, Mumbai, MH, \\ India-400022.
}

Received: 18 Oct 2020 / Accepted: 16 Nov 2020/ Published online: 01 Jan 2021 *Corresponding Author Email: rajesh01ncl@rediffmail.com

\begin{abstract}
The developed reverse phase high-performance liquid chromatographic (RP-HPLC) method for the analysis of Ondansetron tablet dosage form is precise and feasible. The separation was carried out on a Fortis C18 $(4.6 \times 100 \mathrm{~mm}, 2.5 \mu \mathrm{m})$ column, using Methanol: $0.1 \%$ OPA (Orthophosphoric acid) in ratio of 50: $50 \% \mathrm{v} / \mathrm{v}$ as the mobile phase with flow rate at $0.7 \mathrm{~mL} / \mathrm{min}$ and analysis was performed at wavelength $248 \mathrm{~nm}$ at ambient temperature. The injection volume was $20 \mu \mathrm{L}$. The retention time of the drug was $4.77 \mathrm{~min}$. The method produced linear responses in the concentration range of 10 to $50 \mu \mathrm{g} / \mathrm{mL}$. The LOD and LOQ values for HPLC method were found to be 0.11 and $0.32 \mu \mathrm{g} / \mathrm{mL}$ respectively. The method was validated as per ICH norms. The use of short column made method consumable. The method is also cost effective. The proposed method is useful for rapid analysis of Ondansetron in pharmaceutical dosage forms.
\end{abstract}

\section{Keywords}

RP-HPLC, Ondansetron, method development and validation.

$$
* * * * *
$$

\section{INTRODUCTION:}

Ondansetron hydrochloride is chemically 1, 2, 3, 9tetrahydro-9-methyl-3-[(2-methyl1H-imidazol-1-yl) methyl]-4H-carbazol-4-one, monohydrochloride, dihydrate. It represents the class of selective 5-HT3 antagonists which is commonly employed as antiemetic in combination with anti-ulcer and anticancer agents. Ondansetron reduces the activity of the vagus nerve, which deactivates the vomiting center in the medulla oblongata, and also blocks serotonin receptors in the chemoreceptor trigger zone. It has little effect on vomiting caused by motion sickness, and does not have any effect on dopamine receptors or muscarinic receptors ${ }^{[1]}$.
The spectroscopic methods such as UV ${ }^{[2-5]}$, visible ${ }^{[6,}$ 7] were reported for Ondansetron in pharmaceutical dosage forms. The quantitative determination of Ondansetron in combination by HPLC ${ }^{[8-14]}$ technique were reported in Literature. HPTLC ${ }^{[15]}$ and LC- MS ${ }^{[16]}$ methods were also reported for the estimation of Ondansetron. Generally shorter columns are used for simple separation and large column used for separation of complex sample. Both the separation and efficiency affected by the column length. The column efficiency tends to decrease with length however; shorter column results in shorter analysis time ${ }^{[17]}$. The present work describes a new, simple and accurate reverse phase liquid chromatographic method for the estimation of Ondansetron in 
pharmaceutical tablet dosage form. The developed method was validated to ensure the compliance in accordance with ICH guidelines ${ }^{[18]}$.

\section{MATERIAL \& METHOD:}

\section{Chemical}

Ondansetron standard is procured as a gift sample from Ipca Laboratories Limited, Mumbai. The HPLC Grade solvents such as Methanol and water were purchased from Merck (India) Ltd. Ortho-phosphoric acid of analytical Grade was purchased from Merck, Mumbai. The marketed formulation (Vomiz $4 \mathrm{mg}$ ZYDUS CADILA) was purchased from retail pharmacy in Mumbai (Maharashtra, India).

\section{Instrumentation}

Chromatographic analysis was performed on Agilent Technologies- 1100 Gradient System equipped with UV (DAD) G13148 Detector controlled by CHEMSTATION 10.1 Software, with auto injector. The column Fortis C18 $(4.6 \times 100 \mathrm{~mm}, 2.5 \mu \mathrm{m})$ is used.

\section{Chromatographic conditions}

The chromatographic separation of Ondansetron was carried out on column Fortis C18 (4.6 x 100 mm, $2.5 \mu \mathrm{m}$ ) by using mobile phase vary in the ratio for the development of the HPLC method. The suitability of the solvent system ratio was decided on the basis of the sensitivity of the assay, retention time and tailing factor.

\section{Preparation of standard stock solution}

Weighed accurately about $10 \mathrm{mg}$ of Ondansetron working standard into a $10 \mathrm{~mL}$ volumetric flask and added $7 \mathrm{~mL}$ of Methanol, sonicated to dissolve and make up the volume with Methanol. Further dilutions were made from $0.1 \mathrm{~mL}$ to $0.5 \mathrm{~mL}$ upto the volume $10 \mathrm{~mL}$ with the diluent.

\section{Preparation of sample solution}

Twenty tablets were weighed and crushed. The powdered drug equivalent to $135 \mathrm{mg}$ was transferred in a single vial. $5 \mathrm{~mL}$ of methanol was used to dissolve the powder completely and the volume was made to $10 \mathrm{~mL}$.

\section{Selection of analytical wavelength}

An appropriate dilution of standard stock solution with mobile phase were prepared. The solutions were scanned between the wavelength range 400$200 \mathrm{~nm}$ using the UV spectrophotometer

Methodology [19-24]

The optimized chromatographic separation of Ondansetron was achieved on column Fortis C18 (4.6 x $100 \mathrm{~mm}, 2.5 \mu \mathrm{m}$ ) by using mobile phase composed Methanol: $0.1 \%$ OPA (ortho phosphoric acid) in ratio of 50: $50 \% \mathrm{v} / \mathrm{v}$; at a flow rate of $0.7 \mathrm{~mL} / \mathrm{min}$. Detection of drug was carried out at $248 \mathrm{~nm}$ by using diluent as mobile phase.

\section{Method validation}

The validation parameters like limit of detection, limit of quantitation, linearity, accuracy, precision, robustness were evaluated as per ICH guidelines.

Limit of Detection (LOD) and Limit of Quantification (LOQ)

The LOD and LOQ were separately determined based on the signal to noise ratio. For LOD the $S / N$ ratio was $3: 1$ and for LOQ the ratio was 10:1

\section{Linearity}

Under the optimized conditions, a calibration curve was prepared for Ondansetron. Standard mixture of different concentration were prepared for determining the working range. To assure the concentration range studied is linear the regression equation and correlation coefficient were evaluated. Accuracy

Accuracy was carried out by \% recovery studies at three different concentration levels. To the preanalysed sample solution of Ondansetron, a known amount of standard drug powder of Ondansetron was added to $80,100,120 \%$ level.

Precision

The precision was determined by repeatability and intermediate precision through intra-day precision and inter-day precision study of the method. The intra-day precision was examined by replicating the assay thrice for two levels in the same day whereas the inter-day precision was obtained by assay of three sample sets on different days. The results of precision study were stated in terms of \% RSD.

\section{Robustness}

Robustness of the method was tested by small but deliberate variations of flow rate, mobile phase composition and temperature. Effects of variation in the flow rate and wavelength were studied at two different concentrations.

\section{Analysis of marketed formulation}

The content of the drug was estimated in tablet formulation by the developed and validated HPLC method. Twenty tablets of Vomiz ( $4 \mathrm{mg}$ ) from Zydus Cadila were weighed and crushed to the fine powder. The powdered drug equivalent to $135 \mathrm{mg}$ was transferred in a $10 \mathrm{~mL}$ volumetric flask. $5 \mathrm{~mL}$ of methanol was added and sonicated for $5 \mathrm{~min}$ to dissolve the powder completely and the volume was made to $10 \mathrm{~mL}$. The content of Ondansetron in tablet formulation was determined.

\section{RESULTS AND DISCUSSION: \\ Method development}

The proposed chromatographic method was found to be suitable for effective separation of Ondansetron (Rt- 4.77) with good resolution, peak shape given in the figure 1 . The mobile phase 
composed of Methanol: $0.1 \%$ OPA (Orthophosphoric acid) in ratio of $50: 50 \% \mathrm{v} / \mathrm{v}$, at a flow rate of $0.7 \mathrm{~mL} / \mathrm{min}$ was selected as it gave well resolved peaks of standard Ondansetron. The optimum wavelength $248 \mathrm{~nm}$ selected for detection and quantitation.

\section{Method validation}

\section{Linearity}

The calibration curves were found be linear for the concentration range of $10-50 \mu \mathrm{g} / \mathrm{mL}$. The standard working curve equation for drug was found to be $y=$ $108.69 x+87.827$ with correlation coefficient value $r^{2}=0.9999$. The results of linearity are given in Table1 and Figure- 2.

\section{Recovery studies}

The mean \% recovery at $80,100,120 \%$ of the test concentration along with its statistical validation for Ondansetron given in Table-2. The \% recovery at 80 , 100 , and $120 \%$ was found to be $100.41,99.82$, and 101.58. It was found that the method was accurate as the percent recovery was in the range of $100 \%$ for Ondansetron.

Precision

The repeatability of sample application and measurement of peak area were expressed in terms of $\%$ RSD and was found to be less than $2.0 \%$. The $\%$ RSD of intra-day precision was found to be $0.06,0.07$ and $0.02 \%$ RSD of interday precision was found to be $0.11,0.21$ and 0.18 . The results of precision studies are shown in Table-3 and 4.

\section{Limit of detection and Limit of quantitation}

It was calculated by standard deviation of the response and the slope of calibration curve. LOD and LOQ of the method were calculated and found to be $0.11 \mu \mathrm{g} / \mathrm{mL}$ and $0.32 \mu \mathrm{g} / \mathrm{mL}$.

\section{Robustness}

It was measured by multiple injections of a homogenous sample containing Ondansetron by changing flow rate $0.6 \mathrm{~mL} / \mathrm{min}$ and $0.8 \mathrm{~mL} / \mathrm{min}$ that indicates the performance of the HPLC instrument under chromatographic conditions by changing Wavelength i.e $247 \mathrm{~nm}$ and $249 \mathrm{~nm}$. The method was found to be robust in the range of deliberate changes made. $($ Table- 5,6$)$

\section{Estimation of content of drugs in tablet}

The developed and validated HPLC method estimated that the percent content of Ondansetron in tablet formulation was $99.57 \%$. The detailed data is mentioned in Table- 7.

Table- 1 Linearity data of Ondansetron

\begin{tabular}{ll}
\hline Concentration $\mu \mathrm{g} / \mathrm{mL}$ & Area \\
\hline 10 & 1179.15 \\
20 & 2276.04 \\
30 & 3317.91 \\
40 & 4435.15 \\
50 & 5533.95 \\
\hline
\end{tabular}

Table-2 Recovery data of Ondansetron

\begin{tabular}{llllll}
\hline Level (\%) & Drug Conc $(\mathbf{m g})$ & Amt added $(\mathbf{m g})$ & Total Amt $(\mathbf{m g})$ & Amt recovered $(\mathbf{m g})$ & \% Recovery \\
\hline $80 \%$ & 10 & 8 & 18.03 & 8.03 & 100.41 \\
$100 \%$ & 10 & 10 & 19.98 & 9.98 & 99.82 \\
$120 \%$ & 10 & 12 & 22.03 & 12.03 & 101.58 \\
\hline
\end{tabular}

a) Conc= Concentration, Amt $=$ Amount

Table- 3 Precision study (intra- day) of Ondansetron

\begin{tabular}{lllll}
\hline Conc $\mu \mathrm{g} / \mathrm{MI}$ & Area & AVG & SD & \%RSD \\
\hline \multirow{4}{*}{10} & 1179.54 & & & \\
& 1178.96 & 1179.63 & 0.72 & 0.06 \\
& 1180.40 & & & \\
30 & 3313.68 & & & \\
& 3316.89 & 3316.38 & 2.48 & 0.07 \\
& 3318.56 & & & \\
50 & 5531.37 & & & \\
& 5534.12 & 5533.16 & 1.55 & 0.02 \\
& 5533.98 & & & \\
\hline
\end{tabular}

a) Conc= Concentration

b) $\mathrm{AVG}=$ average, $\mathrm{SD}=$ Standard deviation, $\mathrm{RSD}=$ Relative standard deviation 
Table- 4 Precision study (inter-day) of Ondansetron

\begin{tabular}{lllll}
\hline Conc $\mu \mathrm{g} / \mathrm{mL}$ & Area & AVG & SD & \%RSD \\
\hline \multirow{3}{*}{10} & 1067.42 & & & \\
& 1064.91 & 1065.83 & 1.13 & 0.11 \\
& 1065.15 & & & \\
30 & 3242.58 & & & \\
& 3251.47 & 3250.08 & 6.91 & 0.21 \\
& 3256.20 & & & \\
50 & 5381.89 & & & \\
& 5375.67 & 5373.32 & 9.95 & 0.18 \\
& 5362.40 & & & \\
\hline
\end{tabular}

a) Conc $=$ Concentration

b) $\mathrm{AVG}=$ average, $\mathrm{SD}=\mathrm{Standard}$ deviation, $\mathrm{RSD}=$ Relative standard deviation

Table-5: Robustness study with change in flow rate of Ondansetron

\begin{tabular}{lllll}
\hline Flow rate $\mathrm{mL} / \mathrm{min}$ & Conc $\mu \mathrm{g} / \mathrm{mL}$ & Area & AVG & \%RSD \\
\hline 0.6 & & 3957.32 & & \\
0.6 & 30 & 3965.23 & 3955.88 & 0.26 \\
0.6 & & 3945.10 & & \\
0.8 & & 2960.67 & & \\
0.8 & 30 & 2965.87 & 2966.31 & 0.20 \\
0.8 & & 2972.40 & & \\
\hline
\end{tabular}

a) Conc $=$ Concentration; b) AVG= average, $\mathrm{SD}=$ Standard deviation, $\mathrm{RSD}=$ Relative standard deviation

\begin{tabular}{lllll}
\multicolumn{5}{l}{ Table-6: Robustness study with change in Wavelength of Ondansetron } \\
\hline Wavelength $\mathbf{~ n m}$ & Conc $\boldsymbol{\mu g} / \mathbf{m L}$ & Area & AVG & \%RSD \\
\hline 247 & & 3290.41 & & \\
247 & 30 & 3294.82 & 3293.80 & 0.09 \\
247 & & 3296.30 & & \\
249 & & 3426.78 & & \\
249 & 30 & 3452.69 & 3440.15 & 0.38 \\
249 & & 3440.98 & & \\
\hline
\end{tabular}

a) Conc= Concentration

b) $\mathrm{AVG}=$ average, $\mathrm{SD}=\mathrm{Standard}$ deviation, $\mathrm{RSD}=$ Relative standard deviation

Table-7: Assay Results of Tablet Dosage Form

\begin{tabular}{ll}
\hline Parameter & Ondansetron \\
\hline Label claim amount (mg) & 4 \\
Amount found (mg) & 3.98 \\
$\%$ Content & $99.57 \%$ \\
\hline
\end{tabular}

Figure-1: HPLC Chromatogram with resolved peak of Ondansetron

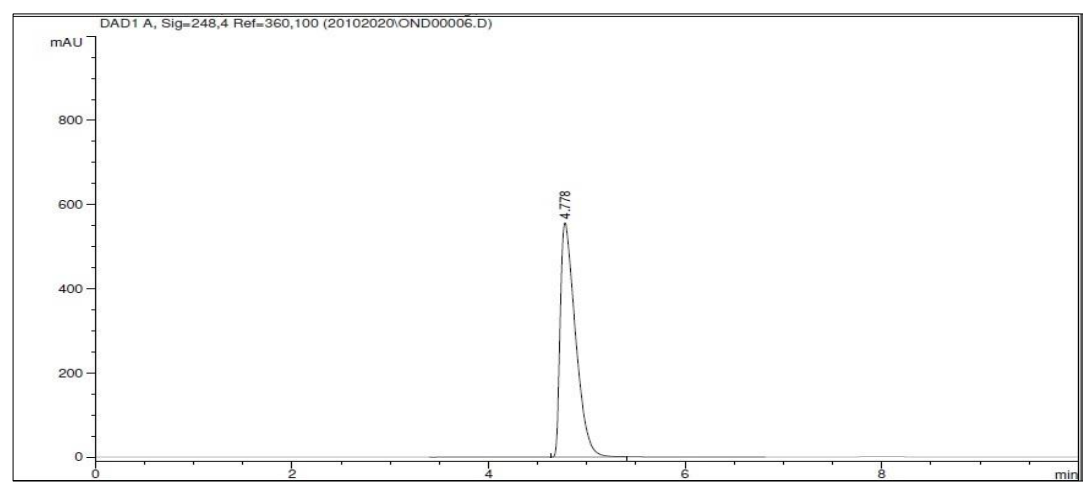




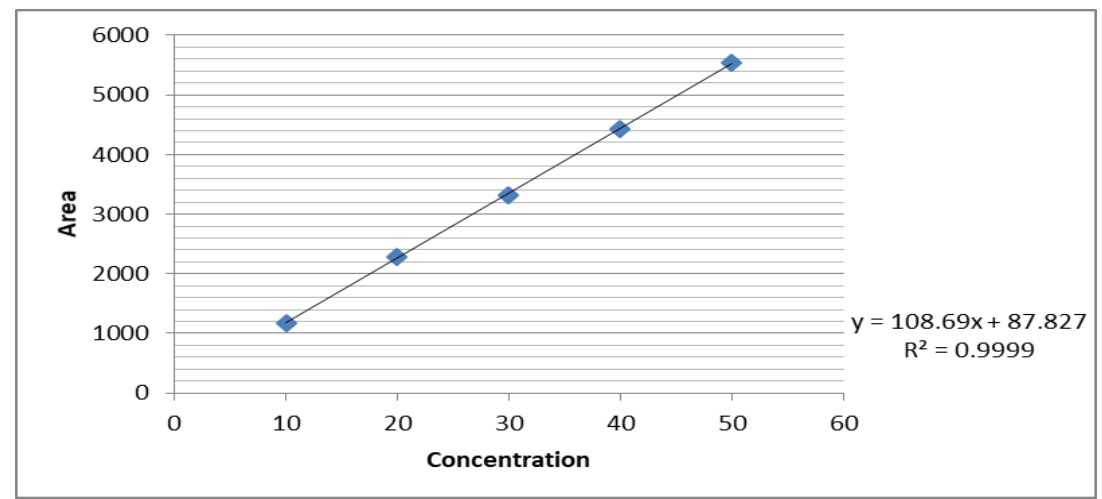

Figure-2: Linearity curve of standard Ondansetron

\section{CONCLUSION:}

The proposed developed method was validated as per ICH guidelines. The use of shorter column results in shorter analysis time (Rt- 4.77). The standard deviation and \% RSD calculated of the proposed method is low, indicating high degree of precision of the method. The results of the recovery studies performed show the high degree of accuracy of the proposed method. Hence, it can be concluded that the developed RP-HPLC method is accurate, precise and selective and can be successfully used for the estimation of Ondansetron in bulk and marketed formulations.

\section{ACKNOWLEDGEMENT:}

The authors are grateful to Ipca Laboratories Limited, Mumbai for providing the gift samples of the drugs and there is no conflict of interest.

\section{REFERENCES:}

1. https://pubchem.ncbi.nlm.nih.gov/compound/Onda nsetron

2. Ravi K P, Murali K M, Bhanu P P. Derivative spectrophotometric estimation of ondansetron and paracetamol. E-Journal of Chemistry. 2006; 3(3): 134136.

3. Patel S, Patel L J. Derivative spectrophotometric method for simultaneous determination of ondansetron and Rabeprazole in combined dosage form. Asian Journal of Pharmaceutical and Clinical Research, 2012; 5(2).

4. Pillai S, Singhvi I. Spectrophotometric simultaneous estimation of ranitidine hydrochloride and ondansetron hydrochloride from tablet formulation. Indian journal of pharmaceutical sciences. 2007; 69(4): 601-604.

5. Ashok Reddy S, Chandra Shekar K B. UV Spectrophotometric method for simultaneous determination of dexa and ondansetron in bulk and combined dosage form. International Journal of Advances in Pharmaceutical Research. Research Paper, 22307583.

6. Raza A, Subhan A. Spectrophotometric Determination of Ondansetron Hydrochloride in Pharmaceutical Bulk and Dosage Forms. Journal of the Chinese Chemical Society. 2007; 54: 223-227.

7. Zamora L. Extractive Spectrophotometric Determination of Ondansetron by lon-Pair Formation with Bromocresol Green. Taylor Francis online. 1996; 29(5):785-792.

8. Sheshala $R$, Darwis $Y$, Khan N. Development and validation of an RP-LC-UV method for the determination of ondansetron Application to pharmaceutical dosage. Chromatographia. 2009; 70: 75-81.

9. Varvara A, Monciu C M. Application of a selective bonded phase in the liquid chromatographic assay of ondansetron hydrochloride and its impurities. Farmacia. 2009; 57: 5.

10. Kelly J W. High-performance liquid chromatographic separation of Ondansetron enantiomers in serum using a cellulose-derivatized stationary phase and solid-phase extraction. J Chromatogr. 1993; 622: 291295.

11. Siluveru M. Enantioselective determination of S-(+) and $\mathrm{R}$-(-)-ondansetron in human serum using derivatized cyclodextrins - modified capillary electrophoresis and solid-phase extraction. J Chromatogr. 1997; 691: 217-222.

12. Patel S R, Patel J, Yogeshvar P. Development and Validation of analytical method for the determination of Rabeprazole and Ondansetron in pharmaceutical dosage form by Reversed-phase HPLC. International Journal of Chem Tech Research. 2010; 2(3): 15311536.

13. Dedania Z, Dedania R, Karkhanis V. RP-HPLC Method for Simultaneous Estimation of Omeprazole and Ondansetron in Combined Dosage Forms. Asian J. Research Chem. 2009; 2(2).

14. Dotsikas Y, KousoulosC, Tsatsou G. Development and validation of a rapid 96-well format based liquidliquid extraction and liquid chromatography-tandem mass spectrometry analysis method for ondansetron in human plasma. J Chromatogr. 2006; 836: 79-82.

15. Raval P B, Wadher S J, and Yeole P G. A Validated HPTLC Method for Determination of Ondansetron in Combination with Omeprazole or Rabeprazole in Solid Dosage Form. Indian journal of pharmaceutical sciences. 2008; 70(3): 386-390.

16. Pang L, Wang Q, Wang Y. Development and Validation of LC-MS/MS Method for Determination of 
Ondansetron in rat Plasma and its Application. Latin American Journal of Pharmacy. 2012; 31(2): 305-9.

17. Koyama J, Nomura J, Shiojima Y, Ohtsu Y, Horii I. Effect of column length and elution mechanism on the separation of proteins by RP- HPLC. Journal of Chromatography. 1992; 625: 217- 222.

18. ICH Q2 (R1). Validation of analytical procedures: text and methodology International Conference on Harmonization. Geneva. 2005; 1-13.

19. Mandale V R, Palekar S S, Patel M V, Borkar N A, Tekade A R, Karnik A M. Development And Validation of RP-HPLC Method for Simultaneous Estimation of Ranitidine and Ondansetron in Pharmaceutical Formulations. World Journal of Pharmaceutical Research. 2015; 4(1): 1872- 1881.

20. Sharmila D, Mahaboobunnisa Md, Lakshmana Rao A. Stability Indicating RP-HPLC Method for Estimation of Pantoprazole and Ondansetron in Pharmaceutical Dosage Form. Int J Pharma Res Health Sci. 2019; 7(5): 3047-3050.
21. Priyanka $\mathrm{CH}$, Lalitha $T$, MadhaviLatha $B$, Satyavati $D$, Abhishiktha V. Analytical Method Development and Validation for Simultaneous Estimation of Ondansetron and Ranitidine in Pure and its Tablet Dosage Form by RP-HPLC. J Pharma Res. 2018; 7(8): 182-185.

22. Atrey E, Shende P, Gaud R S. RP-HPLC Method Development and Validation for Simultaneous Estimation of Ondansetron Hydrochloride and Complexed Famotidine in Bulk and Dosage Form. J Anal Pharm Res. 2017, 5(2): 1-5.

23. Deshmukh $T B$, Deo $S \mathrm{~S}$, Inam $\mathrm{F}$, Lambat $T \mathrm{~L}$, Gurubaxani S B, Choudhari A V. Development and Validation of Ondansetron Hydrochloride in Pharmaceutical Dosage Form by RP-HPLC Method. International Journal of Advances in Science Engineering and Technology. 2015; 1: 15- 20.

24. Manasa G, Prakash K V, Sultana M, Kumari P. Method Development and Validation of Ondansetron by UvVisible Spectrophotometry. IAJPS. 2015; 2(12): 15761780. 